\title{
The Role of Health Education Intervention towards Improving Knowledge, Attitude and Practice of Onchocerciasis in Enugu State, Southern Nigeria
}

\author{
Omotowo Babatunde $\mathrm{I}^{1}$, Ezeoke Uchechukwu E ${ }^{1}$, Ajuba Miriam $\mathrm{O}^{2,}$, Ndu Anne $\mathrm{C}^{1}$, Okafor Ogochukwu $\mathrm{C}^{3}$, Meka \\ Ijeoma $\mathrm{A}^{4} \&$ Eyisi Ifeanyi $\mathrm{G}^{5}$ \\ ${ }^{1}$ Department of Community Medicine, College of Medicine, University of Nigeria, Enugu, Nigeria \\ ${ }^{2}$ Department of Community Medicine, Enugu State University College of Medicine Enugu, Nigeria \\ ${ }^{3}$ National Onchocerciasis Control Programme, Enugu State, Nigeria \\ ${ }^{4}$ Department of Chemical Pathology, College of Medicine, University of Nigeria, Enugu, Nigeria \\ ${ }^{5}$ Department of Community Medicine, College of Medicine, Chukwuemeka Odimegwu Ojukwu University \\ Enugu, Nigeria \\ Correspondence: Ezeoke Uchechukwu E, Department of Community Medicine, College of Medicine, University \\ of Nigeria, Enugu, Nigeria.
}

Received: June 8, 2017 Accepted: July 3, 2017 Online Published: July 27, 2017

doi:10.5539/gjhs.v9n9p145 URL: https://doi.org/10.5539/gjhs.v9n9p145

\begin{abstract}
Background: Onchocerciasis or river blindness constitutes a major burden to households especially in resource-poor settings, causing debilitation and reduction in household productivity. It is an endemic disease in Nigeria. The study aimed to determine the effect of health education on knowledge, attitudes and practices towards onchocerciasis.

Methods: This study was an intervention study carried out among 282 respondents. A multistage sampling technique was used to select the study sample.

Results: Both study and control groups had poor knowledge, $40.4 \%$ and $41.2 \%$ respectively pre-intervention. However, most of the respondents had good practices, but attitudes towards the disease is poor as most respondents do not see onchocerciasis as a serious problem. Knowledge of respondents improved significantly among the study group $\left(\mathrm{X}^{2}=37.814, \mathrm{P}=0.046\right)$ compared to control group $\left(\mathrm{X}^{2}=1.756, \mathrm{P}=0.416\right)$ post-intervention. Also, practices $\left(\mathrm{X}^{2}=21.378, \mathrm{P}=0.039\right)$ towards onchocerciasis improved significantly, but changes in attitudes was not statistically significant post-intervention among study group $\left(\mathrm{X}^{2}=35.908, \mathrm{P}=0.278\right)$.

Conclusions: From our study, health education was shown to improve knowledge and practices on onchocerciasis in the study group compared to control group. Health promotion interventions such as health education campaigns should be scaled-up in onchocerciasis-endemic communities.
\end{abstract}

Keywords: onchocerciasis, health education, knowledge, attitudes, Nigeria

List of Abbreviations

APOC: African Programme for Onchocerciasis Control

CDTI: Community Directed Treatment with Ivermectin

KAP: Knowledge, Attitudes, and Practices

LGA: Local Government Area

CDDs: Community Drug Distributors

FMOH: Federal Ministry of Health

PHWs: Public Health Workers

WHO: World Health Organization 


\section{Background}

Onchocerciasis is a chronic parasitic disease caused by the filarial worm Onchocerca volvulus. The disease is transmitted from man to man through the bites of the blackfly Simulium spp of the family Simulidae (Eezzuduemhoi \& Wilson, 2013). The disease is endmic in 30 African countries, Yemen, and in small foci in Central America and South America (Opara, Usip, \& Akpabio, 2018; World Health Organization, 1995; World Health Organization, 2013). Globally, at least 18 million individuals have onchocerciasis, and $99 \%$ reside in Africa. Also, WHO estimated that 750,000 people are blind or have reduced vision as a result of the disease. West Africa is among the most endemic areas in the world, and Nigeria has the largest number of persons with onchocerciasis, accounting for about a third of the global prevalence, and as one of the largest countries in West Africa she has been reported to have a high incidence of onchocerciasis infection with 7 million persons infected with the disease and 40 million at risk (Opara, Usip, \& Akpabio, 2018). The fear of blindness resulted in depopulation of fertile river valleys, thus onchocerciasis is a major obstacle to socio-economic development in the Savannah regions of West Africa. The fertility of riverine lands and associated high blindness rate are opposing forces which respectively attract and repel human settlement along fast flowing rivers near vector breeding sites.

Although onchocerciasis has existed in Nigeria for centuries, it was not until 1908 that the first report was published (Buddent, 2013). Since then, various authors (World Health Organization, 2015; World Health Organization, 2012; Hoerauf, Buttner, Adjei et al., 2003) have contributed to the existing knowledge of its natural endemicity and the socio-economic importance of the disease. Consequently, many studies have been conducted to assess knowledge, attitude and practices towards onchocerciasis. In a research by Manafa and Isamah conducted in Oji River local government area of Enugu State, Nigeria, questionnaires, focused group discussions and key informant interviews were used to determine the socio-cultural factors affecting the transmission of onchocerciasis The result showed low knowledge about the cause, prevention and complications of onchocerciasis among members of a community. Majority are aware of the disease which they recognized once their bodies starts itching or musculo skeletal pains develops, but only $64.4,34.0,1.4$ and 3.6\% respectively attributed chronic itching, nodules, had vision and leopard skin to blackfly bites (2013, Manafah \& Isamah, 2002).

Knowledge, Attitudes and Practices (KAPs) was low in another recent study in four endemic communities in Ondo State Nigeria, where in-depth interviews were conducted on people's knowledge, attitudes, and practices regarding onchocerciasis. However, health education intervention showed a significant improvement in the knowledge attitudes, and practices (KAP) of the respondents. The knowledge of Onchocerciasis aetiology increased to $79.8 \%$, $71.5 \%, 81.2 \%$ and $74 \%$ from $48.5 \%, 48.7 \%, 34 \%$ and $45.3 \%$ respectively post-intervention. The study demonstrated that a community-based health education can be effective in Onchocerciasis control (Manafa, Awolola, \& Isamah, 2003).

According to World Health Organization (WHO), health education is defined as any combination of learning experience designed to help individuals and communities improve their health by increasing their knowledge or influencing their attitude (Nandha \& Krishnamoorthy, 2011). Health education has been linked to improvement in knowledge, attitude and practices of various diseases, especially vector borne disease such as onchocerciasis (World Health Organization, 2013), and it has been recommended as a way of influencing people's knowledge about onchocerciasis (Ogbuokiri, 2013; Shu, Nwadike, Onwujekwe et al., 1999; Adeoye, Ashaye, \& Onakpoya, 2010). Some studies conducted in Nigeria showed that higher proportion of people had improved knowledge about oncocerciasis post health education intervention (Shu, Okonkwo \& Onyejekwe 2008, Manafa, Awolola, \& Isamah 2003).

Knowledge, Attitudes and practices is crucial for the African Program for Onchoceciasis Control (APOC) to achieve the ultimate goal of reducing the public health and socio-economic problems associated with the disease within a period of 12-15 years using the strategy of yearly community directed treatment with ivermectin (CDTI). It is expected that health education should be designed in such a way as to improve the community awareness of the etiology, symptoms treatment, prevention and control of onchocerciasis and the need to comply with the treatment plan as a strategy for controlling the disease (Mbanefo, Eneanya, \& Nwaorgu, 2010). This study was therefore conducted to determine the effectiveness of health education intervention on the knowledge, attitude and practice on onchocerciasis in this part of Nigeria.

\section{Methods}

\subsection{Study Area}

This study was carried out in Enugu state, Southern Nigeria. The state is made up of 17 LGAs, and has a population of 5,590,513 according 2006 population census. The State is predominantly agricultural with yam tubers, palm 
produce and rice being their main produce (Nigeria Business Directory, 2013).

\subsection{Study Population}

The study population was randomly selected from adult males and females aged 15 years and above. Inclusion Criteria are those who were permanent residents (i.e., residents for at least a year) in each ward in the selected communities.

Visitors from outside the selected communities or staying temporarily and children who were less than 15 years were excluded.

\subsection{Sampling Method}

All the LGAs in Enugu State except Enugu North and Enugu South were reported to be onchocerciasis endemic (Shu, Okonkwo, \& Onwujekwe, 2008). Two LGAs were randomly selected by balloting, then one community was randomly selected from each of the selected LGA. By use of balloting, one community was chosen for the intervention while the other community served as control. Cluster units such as town halls, schools, churches-were randomly selected.

\subsection{Study Design}

This was an intervention study carried out from April to June, 2013. It comprised of a study and a control group. The control group was similar to the study group in terms of endemicity of onchocerciasis, population density and socio-economic status. The community selected as the study group was in Enugu East LGA and the community which served as the control was in Nkanu West LGA. The study was carried out in 3 phases for the study group and 2 phases for the control group a distance of about $10 \mathrm{~km}$ apart.

Phase 1: Two hundred and eighty two (282) respondents participated in the baseline survey.

Phase 2: Health education on onchocerciasis was carried out in the study area only; health education was done in 3 different clusters in the intervention community-the local government council hall, the community town hall and the premises of the community secondary school-in three sessions, each session lasting for 40 minutes, for 3 days.

Phase 3: It took place one month after the intervention in the study area. Same questionnaire as in the baseline survey was administered to the study and control groups.

\subsection{Educational Content of Study Intervention}

Content of the health education intervention included lessons on the causative agent, transmission, clinical manifestations, treatment and control of onchocerciasis. Lessons were delivered both in English and in Igbo (the local dialect). It involved the use of illustrated pictorial materials. Questions were entertained from the participants after each session.

\subsection{Man Power Training and Supervision}

Two field workers (one for each group) helped in administering the questionnaires. The field workers were trained, this is to enhance the validity of the study. The field workers were supervised by the researchers.

\subsection{Data Analysis}

Data were analyzed using Statistical package for social Sciences (SPSS) Inc., Chicago, II, USA and the level of significance was at $5 \%$ confidence.

\subsection{Scoring of Knowledge, Attitude, and Practice}

Ten (10) questions on knowledge of onchocerciasis were scored, each right answer was one point. The scores less than $40 \%$ (0 to 4 points) were poor knowledge; $41 \%$ to $60 \%$ (5 to 6 points) fair knowledge greater than $60 \%$ (greater than 6 poits) good knowledge. The same was done for practice with five (5) key questions. Those who got 3 and above questions right had good practice, while 1 or 2 had poor practice. For attitude, there are three key questions (3) in which those who got all three questions right have good attitude, those who got 2 questions right had fair attitude and those who got only 1 question right had poor attitude.

\subsection{Limitation of the Study}

Mobilization of community members to participate in the health education intervention.

\section{Results}

Two hundred and eight two community members participated in the research, and the response rate was $100 \%$ in the pre-intervention and post intervention. 
Table 1. Demographic characteristics of the participants

\begin{tabular}{|c|c|c|c|c|}
\hline \multirow{2}{*}{ Demographic characteristics } & \multicolumn{2}{|l|}{ Study group } & \multicolumn{2}{|c|}{ Control group } \\
\hline & $\mathrm{N}=141$ & $\%$ & $\mathrm{~N}=141$ & $\%$ \\
\hline \multicolumn{5}{|l|}{ Sex: } \\
\hline Male & 51 & 36.2 & 41 & 29.1 \\
\hline Female & 90 & 63.8 & 100 & 70.9 \\
\hline \multicolumn{5}{|l|}{ Age Group (Years): } \\
\hline $15-24$ & 88 & 62.4 & 78 & 55.3 \\
\hline $25-34$ & 15 & 10.6 & 31 & 22.0 \\
\hline $35-44$ & 18 & 12.8 & 11 & 7.8 \\
\hline $45-54$ & 13 & 9.2 & 15 & 10.6 \\
\hline $55-64$ & 0 & 0.0 & 5 & 3.6 \\
\hline$>64$ & 7 & 5.0 & 1 & 0.7 \\
\hline \multicolumn{5}{|l|}{ Educational status: } \\
\hline No- formal & 12 & 8.5 & 13 & 9.2 \\
\hline Primary & 19 & 13.5 & 15 & 10.6 \\
\hline Secondary & 94 & 66.7 & 74 & 52.5 \\
\hline Tertiary & 16 & 11.3 & 39 & 27.7 \\
\hline \multicolumn{5}{|l|}{ Occupation: } \\
\hline Unemployed & 0 & 0.0 & 22 & 15.6 \\
\hline Student & 80 & 56.7 & 67 & 47.5 \\
\hline Farming & 27 & 19.1 & 11 & 7.8 \\
\hline Trading & 5 & 3.6 & 10 & 7.1 \\
\hline Civil servants & 28 & 19.9 & 29 & 20.6 \\
\hline Others & 1 & 0.7 & 1 & 1.4 \\
\hline \multicolumn{5}{|l|}{ Marital status: } \\
\hline Married & 46 & 32.6 & 43 & 30.5 \\
\hline Single & 89 & 63.1 & 93 & 66.0 \\
\hline Divorced/separated & 0 & 0.0 & 2 & 1.4 \\
\hline Widowed & 6 & 4.3 & 3 & 2.1 \\
\hline \multicolumn{5}{|l|}{ Tribe: } \\
\hline Igbo & 140 & 99.3 & 134 & 95.1 \\
\hline Yoruba & 1 & 0.7 & 4 & 2.8 \\
\hline Others & 0 & 0.0 & 3 & 2.1 \\
\hline \multicolumn{5}{|l|}{ Religion: } \\
\hline Christianity & 139 & 98.6 & 141 & 100.0 \\
\hline Islam & 1 & 0.7 & 0 & 0.0 \\
\hline Others & 1 & 0.7 & 0 & 0.0 \\
\hline
\end{tabular}

Table 1 shows Two hundred and eight two (282) persons participated in the study of which 141 belonged to the study group and 141 to the control group. Majority are females in the study group $63.8 \%$ and control group $70.9 \%$. The mean age is $28.0 \pm 13.8$ for the study group and $28.32 \pm 11.8$ for the control group. 
Table 2. Knowledge of respondents on Onchocerciasis

\begin{tabular}{|c|c|c|c|c|}
\hline \multirow{2}{*}{ Variables } & \multicolumn{2}{|l|}{ Study group } & \multicolumn{2}{|c|}{ Control group } \\
\hline & $\mathrm{N}=141$ & $\%$ & $N=141$ & $\%$ \\
\hline \multicolumn{5}{|l|}{ What is Onchocerciasis: } \\
\hline Disease & 57 & 40.4 & 58 & 41.2 \\
\hline Type of blindness & 41 & 29.1 & 56 & 39.7 \\
\hline River & 37 & 26.3 & 20 & 14.2 \\
\hline Drug & 1 & 0.7 & 2 & 1.4 \\
\hline Fly & 1 & 0.7 & 1 & 0.7 \\
\hline Not known & 4 & 2.8 & 4 & 2.8 \\
\hline \multicolumn{5}{|l|}{ Symptoms of onchocerciasis: } \\
\hline Stooling and vomiting & 47 & 33.3 & 37 & 26.2 \\
\hline Blindness & 41 & 29.1 & 38 & 27.0 \\
\hline Nodules & 23 & 16.3 & 20 & 14.2 \\
\hline Leopard skin & 11 & 7.8 & 5 & 2.5 \\
\hline Rashes & 13 & 9.2 & 19 & 13.5 \\
\hline Not known & 6 & 4.3 & 22 & 15.6 \\
\hline \multicolumn{5}{|l|}{ Causes of onchocerciasis: } \\
\hline Contaminated food/water & 43 & 30.5 & 32 & 22.7 \\
\hline Bite of black fly & 34 & 24.6 & 35 & 24.8 \\
\hline Mosquito bite & 29 & 20.6 & 15 & 10.6 \\
\hline Contact with infected person & 7 & 5.0 & 13 & 9.2 \\
\hline Witchcraft & 19 & 13.5 & 25 & 17.7 \\
\hline Not known & 9 & 6.4 & 21 & 15.0 \\
\hline \multicolumn{5}{|l|}{ Prevention of onchocercisis; } \\
\hline Drinking clean water & 55 & 39.0 & 44 & 31.2 \\
\hline Protection from mosquitoes & 30 & 21.3 & 10 & 7.1 \\
\hline Protection from black flies & 27 & 19.1 & 46 & 32.6 \\
\hline Avoid contact with infected person & 9 & 6.4 & 15 & 10.6 \\
\hline Not known & 20 & 14.2 & 26 & 18.5 \\
\hline \multicolumn{5}{|l|}{ Choice of drugs: } \\
\hline Ivermectin & 78 & 55.3 & 71 & 50.3 \\
\hline Malaria tablets & 27 & 19.1 & 10 & 7.1 \\
\hline Haematinics & 16 & 11.4 & 18 & 12.8 \\
\hline Herbs and concortions & 9 & 6.4 & 15 & 10.6 \\
\hline Not known & 11 & 7.8 & 27 & 19.2 \\
\hline
\end{tabular}

Table 2 shows that $40.4 \%$ and $41.2 \%$ of respondents in study and control groups respectively knew that onchocerciasis is a disease. Among the study group, $36.2 \%$ of respondents believed that onchocerciasis is caused by drinking contaminated water, while it was $29.8 \%$ in control group. Study group (30.5\%) believed that River Blindness is transmitted through contaminated food/water, while Control group (24.8\%) knew that the disease is transmitted through the bite of the black fly. $13.5 \%$ and $17.7 \%$ of study group and control group respectively believed witchcraft is the cause of onchocerciasis. 
Table 3. Heard of onchocerciasis and sources of information by the respondents

\begin{tabular}{|c|c|c|c|c|}
\hline \multirow{2}{*}{ Variables } & \multicolumn{2}{|l|}{ Study group } & \multicolumn{2}{|c|}{ Control group } \\
\hline & $N=141$ & $\%$ & $N=141$ & $\%$ \\
\hline \multicolumn{5}{|c|}{ Heard of onchocerciasis before: } \\
\hline Yes & 71 & 50.4 & 90 & 64.0 \\
\hline No & 70 & 49.6 & 51 & 36.0 \\
\hline \multicolumn{5}{|c|}{ Sources of information: } \\
\hline Health worker & 21 & 30.4 & 17 & 19.1 \\
\hline Radio/Television & 13 & 18.4 & 29 & 31.9 \\
\hline Neighbor & 2 & 2.8 & 4 & 4.3 \\
\hline School & 13 & 18.4 & 19 & 21.3 \\
\hline Church & 3 & 3.6 & 9 & 10.6 \\
\hline No idea & 18 & 26.2 & 12 & 12.8 \\
\hline
\end{tabular}

Table 3 shows that $50.4 \%$ and $64 \%$ of respondents among the study and control groups respectively had heard onchocerciasis. Health workers $30.4 \%$ were the major sources of information for study group, while it was radio/television $31.9 \%$ for the control group. 
Table 4. Respondent's attitudes and practices towards onchocerciasis

\begin{tabular}{|c|c|c|c|c|}
\hline \multirow{2}{*}{ Variables } & \multicolumn{2}{|c|}{ Study group } & \multicolumn{2}{|c|}{ Control group } \\
\hline & $\mathrm{N}=\mathbf{1 4 1}$ & $\%$ & $\mathrm{~N}=\mathbf{1 4 1}$ & $\%$ \\
\hline \multicolumn{5}{|c|}{ Is it important to know more about onchocerciasis? } \\
\hline Yes & 102 & 72.3 & 137 & 97.2 \\
\hline No & 23 & 16.3 & 4 & 2.8 \\
\hline Don’t know & 16 & 1.4 & 0 & 0.0 \\
\hline \multicolumn{5}{|c|}{ Are you satisfied with receiving drugs from CDDs? } \\
\hline Yes & 59 & 42.0 & 42 & 30.0 \\
\hline No & 82 & 58.0 & 99 & 70.0 \\
\hline \multicolumn{5}{|c|}{ Do you think it is important to take drugs as at when given by CDDs? } \\
\hline Yes & 110 & 78.0 & 124 & 84.9 \\
\hline No & 31 & 22.0 & 17 & 12.1 \\
\hline \multicolumn{5}{|c|}{ Have you participated in the CDTI program before? } \\
\hline Yes & 35 & 25.0 & 21 & 15.0 \\
\hline No & 106 & 75.0 & 120 & 85.0 \\
\hline \multicolumn{5}{|c|}{ Do you take the drug Mectizan? } \\
\hline Yes & 61 & 43.3 & 43 & 30.5 \\
\hline No & 80 & 56.7 & 98 & 69.5 \\
\hline \multicolumn{5}{|c|}{ Do black flies interfere with your occupation/ } \\
\hline Yes & 48 & 34.0 & 31 & 22.0 \\
\hline No & 26 & 18.5 & 59 & 41.8 \\
\hline Not known & 67 & 47.5 & 51 & 36.2 \\
\hline \multicolumn{5}{|c|}{ Do you control the black flies? } \\
\hline Yes & 117 & 83.0 & 55 & 39.0 \\
\hline No & 24 & 17.0 & 86 & 61.0 \\
\hline \multicolumn{5}{|c|}{ Have you missed any dosing round for ivermectin before } \\
\hline Yes & 65 & 46.1 & 42 & 29.8 \\
\hline No & 76 & 53.9 & 99 & 70.2 \\
\hline \multicolumn{5}{|c|}{ Do you have challenges getting drugs from the CDDs? } \\
\hline Yes & 34 & 24.0 & 37 & 26.0 \\
\hline No & 107 & 76.0 & 104 & 74.0 \\
\hline
\end{tabular}

Table 4 shows that most respondents in the study group (78.0\%) and control group (84.9\%) think it is important to take the drugs as at when given by the CDDs. Majority of the respondents both in the study an control groups, $75 \%$ and $85 \%$ respectively have not participated in the CDTI Programme at one time or the other before. In addition, majority of the respondents in the study group (56.7\%) and in the control group (69.5\%) claimed that they do not take ivermectin. 
Table 5. Effect of Health Education on knowledge, attitude and Practices towards onchocerciasis

\begin{tabular}{|c|c|c|c|c|c|c|c|c|c|c|c|c|}
\hline \multirow{3}{*}{ Variables } & \multicolumn{8}{|c|}{ Study Group } & \multicolumn{4}{|c|}{ Control Group } \\
\hline & \multicolumn{2}{|c|}{ Pre-Intervention } & \multicolumn{2}{|c|}{ Post-Intervention } & \multirow{2}{*}{$\mathrm{X}^{2}$} & \multirow{2}{*}{ P-Value } & \multicolumn{2}{|c|}{ Pre-Intervention } & \multicolumn{2}{|c|}{ Post-Intervention } & \multirow{2}{*}{$\mathrm{X}^{2}$} & \multirow{2}{*}{ P-Value } \\
\hline & $\mathrm{N}$ & $\%$ & $\mathrm{~N}$ & $\%$ & & & $\mathrm{~N}$ & $\%$ & $\mathrm{~N}$ & $\%$ & & \\
\hline \multicolumn{13}{|l|}{ What is Onchocerciasis: } \\
\hline Disease & 57 & 40.4 & 88 & 26.4 & & & 58 & 41.2 & 62 & 44.0 & & \\
\hline Type of blindness & 41 & 29.1 & 21 & 15.0 & & & 56 & 39.7 & 53 & 37.6 & & \\
\hline River & 37 & 26.3 & 14 & 10.0 & & & 20 & 14.2 & 21 & 14.9 & & \\
\hline Drug & 1 & 0.7 & 8 & 5.7 & \multirow{3}{*}{27.879} & \multirow{3}{*}{0.038} & 2 & 1.4 & 1 & 0.7 & \multirow{3}{*}{5.153} & \multirow{3}{*}{0.094} \\
\hline Fly & 1 & 0.7 & 9 & 6.4 & & & 1 & 0.7 & 3 & 2.1 & & \\
\hline Not known & 4 & 2.8 & 1 & 0.7 & & & 4 & 2.8 & 1 & 0.7 & & \\
\hline \multicolumn{13}{|c|}{ What causes onchocerciasis? } \\
\hline $\begin{array}{l}\text { Drinking contaminated } \\
\text { water }\end{array}$ & 43 & 30.5 & 13 & 9.2 & \multirow{6}{*}{46.851} & \multirow{6}{*}{0.047} & 32 & 22.7 & 35 & 24.8 & \multirow{6}{*}{7.657} & \multirow{6}{*}{0.634} \\
\hline $\begin{array}{l}\text { Bad blood from } \\
\text { mosquitoes }\end{array}$ & 34 & 24.6 & 35 & 24.8 & & & 35 & 24.8 & 20 & 14.2 & & \\
\hline Filarial worm (Arikwa) & 29 & 20.6 & 55 & 39.0 & & & 15 & 10.6 & 43 & 30.5 & & \\
\hline Strange body sensations & 7 & 5.0 & 12 & 8.5 & & & 13 & 9.2 & 14 & 10.0 & & \\
\hline Witcheraft & 19 & 13.5 & 8 & 5.7 & & & 25 & 17.7 & 4 & 2.8 & & \\
\hline Not known & 9 & 6.4 & 17 & 12.0 & & & 21 & 15.0 & 25 & 17.7 & & \\
\hline \multicolumn{13}{|c|}{ Transmission of onchocarciasis: } \\
\hline $\begin{array}{l}\text { Through contaminated } \\
\text { food/water }\end{array}$ & 34 & 24.0 & 85 & 60.3 & \multirow{5}{*}{16.296} & \multirow{5}{*}{0.037} & 35 & 24.8 & 49 & 34.8 & \multirow{5}{*}{16.296} & \multirow{5}{*}{0.079} \\
\hline Through mosquito bite & 29 & 20.6 & 22 & 15.6 & & & 15 & 10.6 & 13 & 9.2 & & \\
\hline $\begin{array}{l}\text { Contact with infected } \\
\text { person }\end{array}$ & 50 & 35.5 & 7 & 5.0 & & & 13 & 9.2 & 1 & 0.7 & & \\
\hline Can not be transmitted & 19 & 13.5 & 12 & 8.5 & & & 25 & 17.7 & 22 & 15.6 & & \\
\hline Not known & 9 & 6.4 & 7 & 4.9 & & & 21 & 15.0 & 32 & 22.7 & & \\
\hline Drug of choice for infect & ed pers & & & & & & & & & & & \\
\hline Ivermectin (Mectizan) & 78 & 55.3 & 103 & 73.3 & & & 71 & 50.3 & 75 & 53.2 & & \\
\hline Malaria tablets & 27 & 19.1 & 10 & 7.1 & & & 10 & 7.1 & 5 & 3.5 & & \\
\hline Haematinics & 16 & 11.4 & 2 & 1.4 & 22.395 & 0.0246 & 18 & 12.8 & 18 & 12.8 & 8.554 & 0.086 \\
\hline Herbs and concortions & 9 & 6.4 & 10 & 7.1 & & & 15 & 10.6 & 15 & 10.6 & & \\
\hline Not known & 11 & 7.8 & 16 & 4.2 & & & 27 & 19.2 & 28 & 19.9 & & \\
\hline Is it important to know $\mathrm{m}$ & ore $\mathrm{ab}$ & t onchoce & ciasis? & & & & & & & & & \\
\hline Yes & 102 & 72.3 & 119 & 84.4 & & & 137 & 97.2 & 113 & 80.2 & & \\
\hline No & 23 & 16.3 & 22 & 15.6 & 17.331 & 0.043 & 4 & 2.8 & 16 & 11.3 & 21.066 & 0.028 \\
\hline Don't know & 16 & 11.4 & 0 & 0.0 & & & 0 & 0.0 & 12 & 8.5 & & \\
\hline
\end{tabular}

Table 5 shows there is a statistically significant difference between pre and post intervention among study group on the knowledge of what is onchocerciasis $\left(X^{2}=27.879, \mathrm{df}=4, \mathrm{P}=0.038\right)$, the causative agent of onchocerciasis $\left(\mathrm{X}^{2}=46.851, \mathrm{df}=5, \mathrm{P}=0.047\right)$ and mode of transmission of onchocerciasis $\left(\mathrm{X}^{2}=16.296, \mathrm{df}=5, \mathrm{P}=0.037\right)$. In the control group, there is no statistically significant difference in their response on the knowledge of what is onchocerciasis $\left(\mathrm{X}^{2}=5.153, \mathrm{df}=4, \mathrm{P}=0.094\right)$, the causative agent of onchocerciasis $\left(\mathrm{X}^{2}=7.657, \mathrm{df}=5, \mathrm{P}=0.634\right)$ and mode of transmission $\left(\mathrm{X}^{2}=16.296, \mathrm{df}=5, \mathrm{P}=0.079\right)$. 
Table 6. Knowledge, Attitude and Practices of Respondents Before and after Health Education

\begin{tabular}{|c|c|c|c|c|c|c|c|c|c|c|c|c|}
\hline \multirow{3}{*}{ Variables } & \multicolumn{4}{|c|}{ Study Group } & \multirow{3}{*}{$X^{2}$} & \multirow{3}{*}{ P-Value } & \multicolumn{6}{|c|}{ Control Group } \\
\hline & \multicolumn{2}{|c|}{ Pre-Intervention } & \multicolumn{2}{|c|}{ Post-Intervention } & & & \multicolumn{2}{|c|}{ Pre-Intervention } & \multicolumn{2}{|c|}{ Post-Intervention } & \multirow{2}{*}{$\mathrm{X}^{2}$} & \multirow{2}{*}{ P-Value } \\
\hline & $\mathrm{N}$ & $\%$ & $\mathrm{~N}$ & $\%$ & & & $\mathrm{~N}$ & $\%$ & $\mathrm{~N}$ & $\%$ & & \\
\hline \multicolumn{13}{|c|}{ Knowledge of Respondents } \\
\hline Poor & 49 & 30.0 & 20 & 14.2 & \multirow{3}{*}{37.814} & \multirow{3}{*}{0.046} & 42 & 29.8 & 43 & 30.5 & \multirow{3}{*}{1.756} & \multirow{3}{*}{0.416} \\
\hline Fair & 72 & 51.0 & 57 & 40.4 & & & 76 & 53.9 & 67 & 47.5 & & \\
\hline Good & 20 & 14.0 & 64 & 45.5 & & & 23 & 16.3 & 31 & 22.0 & & \\
\hline \multicolumn{13}{|c|}{ Attitude of Respondents } \\
\hline Poor & 80 & 56.7 & 81 & 57.5 & \multirow{3}{*}{35.908} & \multirow{3}{*}{0.278} & 99 & 70.2 & 106 & 75.2 & \multirow{3}{*}{1.757} & \multirow{3}{*}{0.415} \\
\hline Fair & 36 & 25.5 & 34 & 24.1 & & & 27 & 19.2 & 26 & 18.4 & & \\
\hline Good & 25 & 17.8 & 26 & 14.2 & & & 15 & 10.6 & 9 & 6.4 & & \\
\hline \multicolumn{13}{|c|}{ Practice of Respondents } \\
\hline Good & 117 & 82.9 & 113 & 80.0 & \multirow{2}{*}{21.378} & \multirow{2}{*}{0.539} & 65 & 48.9 & 66 & 46.8 & \multirow{2}{*}{12.532} & \multirow{2}{*}{0.246} \\
\hline Poor & 24 & 17.1 & 28 & 20.0 & & & 76 & 51.1 & 75 & 53.2 & & \\
\hline
\end{tabular}

Table 6 shows that there is a statistically significant difference in knowledge of respondents in the study group before and after intervention $\left(\mathrm{x}^{2}=37.814, \mathrm{P}=0.046\right)$, while there is no statistically significant difference in the knowledge of Respondents in control group before and after intervention $\left(x^{2}=1.756, p=0.416\right)$. On the attitude of respondents there is no statistically significant difference in the study group and control group before and after intervention $\left(\mathrm{x}^{2}=35.908, \mathrm{P}=0.278\right)$ and $\left(\mathrm{x}^{2}=1.757, \mathrm{P}=0.415\right)$ respectively. There is also, no statistically significant difference in the practice of respondents in the study and control groups before and after intervention $\left(\mathrm{x}^{2}=21.378, \mathrm{P}=0.539\right)$ and $\left(\mathrm{x}^{2}=12.532, \mathrm{P}=0.246\right)$ respectively.

Table 7. Effect of Educational status on the Knowledge, Attitude and Practices of Respondents in study and control groups before intervention

\begin{tabular}{|c|c|c|c|c|c|c|c|c|c|c|c|c|c|c|}
\hline \multirow{3}{*}{ Variables } & \multicolumn{13}{|c|}{ Knowledge } & \multirow{3}{*}{$P$ value } \\
\hline & \multicolumn{2}{|c|}{ Study Group } & \multirow{2}{*}{$\begin{array}{l}\text { Poor } \\
\mathrm{N}\end{array}$} & \multirow{2}{*}{$\begin{array}{l}\text { Fair } \\
\mathrm{N}\end{array}$} & \multirow{2}{*}{$\begin{array}{l}\text { Good } \\
\mathrm{N}\end{array}$} & \multirow{2}{*}{$\mathrm{X}^{2}$} & \multirow{2}{*}{ P Value } & \multicolumn{2}{|c|}{ Control Group } & \multirow{2}{*}{$\begin{array}{l}\text { Poor } \\
\mathrm{N}\end{array}$} & \multirow{2}{*}{$\begin{array}{l}\text { Fair } \\
\mathrm{N}\end{array}$} & \multirow{2}{*}{$\begin{array}{l}\text { Good } \\
\mathrm{N}\end{array}$} & \multirow{2}{*}{$X^{2}$} & \\
\hline & $\mathrm{N}$ & $\%$ & & & & & & $\mathrm{~N}$ & $\%$ & & & & & \\
\hline \multicolumn{14}{|c|}{ Educational Status } & \multirow{5}{*}{0.026} \\
\hline Non-formal & 12 & 8.5 & 6 & 4 & 2 & & & 13 & 9.2 & 4 & 5 & 4 & \multirow{4}{*}{33.237} & \\
\hline Primary & 19 & 13.5 & 9 & 7 & 3 & 23.452 & 0.032 & 15 & 10.6 & 4 & 6 & 5 & & \\
\hline Secondary & 94 & 66.7 & 31 & 28 & 35 & & & 74 & 52.5 & 29 & 19 & 26 & & \\
\hline Tertiary & 6 & 11.3 & 1 & 1 & 4 & & & 39 & 27.7 & & & & & \\
\hline \multicolumn{15}{|l|}{ Attitude } \\
\hline Non formal & 12 & 8.5 & 7 & 4 & 1 & \multirow{4}{*}{15.259} & \multirow{4}{*}{0.018} & 13 & 9.2 & 3 & 5 & 5 & \multirow{4}{*}{21.872} & \multirow{4}{*}{0.037} \\
\hline Primary & 19 & 13.5 & 12 & 4 & 3 & & & 15 & 10.6 & 4 & 4 & 7 & & \\
\hline Secondary & 94 & 66.7 & 27 & 37 & 30 & & & 74 & 52.5 & 28 & 16 & 30 & & \\
\hline Tertiary & 6 & 11.3 & 1 & 2 & 3 & & & 39 & 27.7 & 7 & 12 & 20 & & \\
\hline \multicolumn{15}{|l|}{ Practice } \\
\hline Non formal & 12 & 8.5 & 5 & 3 & 4 & \multirow{4}{*}{3.176} & \multirow{4}{*}{0.038} & 13 & 9.2 & 7 & 3 & 3 & \multirow{4}{*}{8.793} & \multirow{4}{*}{0.042} \\
\hline Primary & 19 & 13.5 & 9 & 4 & 6 & & & 15 & 10.6 & 6 & 7 & 2 & & \\
\hline Secondary & 94 & 66.7 & 22 & 30 & 4 & & & 74 & 52.5 & 24 & 18 & 3 & & \\
\hline Tertiary & 6 & 11.3 & 0 & 2 & 4 & & & 39 & 27.7 & 2 & 14 & 23 & & \\
\hline
\end{tabular}


Table 7 shows that the effect of educational status on knowledge $\left(\mathrm{x}^{2}=23.452, \mathrm{P}=0.032\right)$, attitude $\left(\mathrm{x}^{2}=15.259\right.$, $\mathrm{P}=0.018)$ and practice $\left(\mathrm{x}^{2}=3.176, \mathrm{P}=0.038\right)$ of Respondent is statistically significant in both the study and control groups.

Table 8. Effect of occupation on the Knowledge, Attitude and Practices of Respondents in study and control groups before intervention

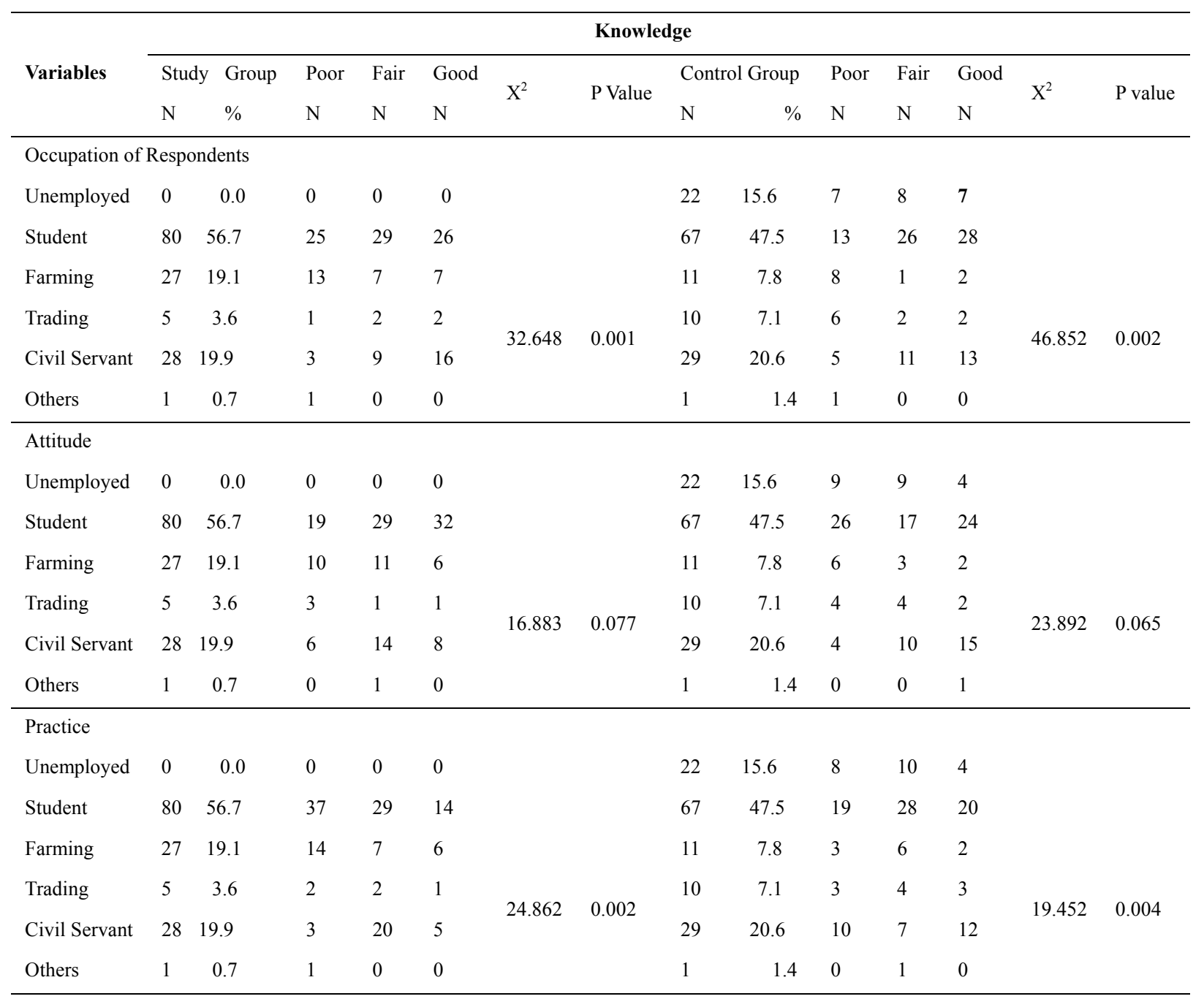

Table 8 shows that the effect of occupation on knowledge $\left(\mathrm{x}^{2}=32.648, \mathrm{P}=0.001\right)$ and practice $\left(\mathrm{x}^{2}=24.862\right.$, $\mathrm{P}=0.002$ ) of Respondents is statistically significant in both the study and control groups. However, its effect on attitude is not statistically significant in both the study and control groups $\left(\mathrm{x}^{2}=16.883, \mathrm{p}=0.077\right)$.

\section{Discussion}

Our study examined the effect of health education intervention towards improving the knowledge, attitudes and practice (KAP) on onchocerciasis among residents of Enugu State. Most respondents in the study and control groups pre-intervention knew that onchocerciasis is a disease and that blindness is one of the symptoms of the disease. This may probably be due to the endemicity of the disease in the study area. However, majority of the respondents in both the study and control groups, 51 (36.2\%) and $42(29.8 \%)$ respectively believed that onchocerciasis is caused by drinking of contaminated water. This study also revealed that a good number of the respondents do not know the mode of transmission of onchocerciasis. Only $34(24.0 \%)$ in the study group and 35 (24.8\%) in the control group that onchocerciasis can be transmitted through black flies. Majority of the respondents both in the study group 43 (30.5\%) and in the control group $32(22.7 \%)$ believed that the disease can be transmitted through contaminated food and water. Misconceptions about the mode of transmission of onchocerciasis by majority of the respondents in this study is consistent with the findings of a study conducted in 
Quara District, North Western Ethiopia, in which majority of the participants held at lease one misconception about the mode of transmission of disease (Weldegereal, Medhin, \& Weldegbriel, 2014). Majority of the respondents $78(55.3 \%)$ in the study group and $71(50.3 \%)$ in the control group, however, knew that ivermectin (Mectizam) is the choice drug for treatment of onchocerciasis. This high percentage of knowledge of ivermectin as choice drug for treatment of onchocerciasis and the corresponding significant increase in the knowledge of ivermectin as choice drug for treatment of onchocerciasis after the health education intervention show that the CDDs and other public health workers (PHWs) concentrate more on the treatment aspect of their job which includes public health education on the aetiology and control of the disease. This is similar to the findings in a study by Brieger et al in which the post-intervention showed an increase in the number of villagers from $1.6 \%$ to $19.3 \%$ who could identify tablets as a form of treatment, and this also showed that PHWs concentrate on the treatment aspect of their job (Brieger, Ramakrishna, \& Adeniyi, 2008).

In our study, majority of the respondents both in the study group $80(56.8 \%)$ and the control group $98(69.5 \%)$ do not take ivermectin. Among those that do not take ivermection, $14(17.5 \%)$ in the study group and $20(20.4 \%)$ in the control group believed incompetence of the CDDs was the reason for not taking the drug. These findings may be attributed to poor health seeking behavior similar to the findings of a study by Adeoye et al which showed that respondents do not see onchocerciasis as a serious health problem (Manafa, Awolola, \& Isamah, 2003). Those who claimed to control the vector in the study group and control groups was $117(83.0 \%)$ and $79(56 \%)$ respecively. Most respondents claimed that they protect themselves from the bites of black flies by putting on clothes that covers the arms and goes down to the ankles e.g, long sleeve shirts and trousers, wrappers etc.

The respondents in the study group showed a statistically significant difference in their response before and after the health education intervention concerning the knowledge on onchocercisis. Our findings are similar to what was reported in a study among school children in Okpatu, Nigeria, where a statistically significant higher proportion of the children knew about causative agent, clinical manifestation, diagnosis, treatment, and prevention of onchocerciasis post intervention (Shu, Okonkwo, \& Onwujekwe, 2008). Our study also revealed that only 26 $(14.0 \%)$ and $23(16.3 \%)$ of respondents in the study and control groups respectively have good knowledge, and only $25(17.8 \%)$ and $15(10.6 \%)$ have good attitude towards onchocerciasis both in the study group and in the control group. This is consistent with the findings of a study by Weldegebreal et al, where the values for good knowledge and attitude were below average (Brieger, Ramakrishna, \& Adeniyi, 2008). Another study reported a significant increase in knowledge of respondents, when the results of the pre-intervention was compared to post intervention survey, which took place about one month after the health education intervention among the study group (Aireen, 2014). However, the findings of our study showed there was no significant increase in the attitude and practice of respondents before and after health education intervention. This is contrary to the result of the study conducted in Osse, Ondo State Nigeria, where a significant increase in the knowledge, attitude and practice of respondents was reported (Manafa, Awolola, \& Isamah, 2003). However the difference could be attributed to difference in socio-cultural beliefs and health seeking behavious of the respondents. The findings of this study showed that the effect of Educational status on knowledge, attitude and practice was statistically significant in the study and control groups. Also in this study, occupation was shown to have a statistically significant effect in knowledge and practice, but not on attitude.

\section{Conclusion}

Majority of the respondents in this study do not have good knowledge and attitude on onchocerciasis. However, most of the respondents have good practice on the disease which is mostly due to protection from the flies during occupational activities and the CDDs concentration on the treatment aspect of their job. From this study, health education was shown to significantly improve knowledge on onchocerciasis in the study group, which can subsequently influence their attitude and practice.

\section{Recommendations}

In view of the findings from this study, it is recommended that regular community-based health education become an important part of the onchocerciasis control programme.

Community Directed Distributors and other health workers in these communities should not only focus on the distribution aspect of the CDTI programme, but should equally focus on conducting health education, just before the drug distribution exercise, in order to sensitize and improve participation of community members.

\section{Ethics Approval and Consent to Participate}

Approval for the study was obtained from the ethical committee of the University of Nigeria Teaching Hospital, Enugu. Written consent was obtained from all respondents. The same type of health education given to the 
intervention group was offered to the control group at the end of the study.

\section{Consent to Publish}

All aurhors consented to publish in the Global Journal of Health Science.

\section{Availability of Data and Materials}

Some materials such as administered questionnaires are still available, but the data stored in SPSS is not longer available. The research was conducted about two years ago

\section{Funding}

The research funded by the authors. No external funding.

\section{Authors Contribution}

Omotowo participated in study design, analysis, interpretation and revised the manuscript. Ezeoke participated in study design and revised the manuscript. Ajuba participated in data collection, analysis. Ogochukwu participated in study design, data collection and written the manuscript, while Meka participated in data collection and analysis. Eyisi participated in study design and data analysis. All authors read and approved the final manuscript.

\section{Acknowledgements}

We are grateful to the community leaders and study participants.

\section{Competing Interests Statement}

The authors declare that there are no competing or potential conflicts of interest.

\section{References}

Adeoye, A. O., Ashaye, A. O., \& Onakpoya, H. (2010). Perception and Attitude of People Toward Onchocerciasis (River Blindness) in South Western Nigeria. Middle East Afr J Opthamol; 17(4), 314. https://doi.org/10.4103/0974-9233.71594

Aireen, M. C. (2014). The effect of health education on the knowledge, attitudes and practices (KAP) on the mothers on Diarrhea in Barangay Paglaun, Dumalinao, Zamboang Del Sur. Retrieved August 7, 2016, from www.ipmnchnprojectmindanao.or

Brieger, W. R., Ramakrishna, J., Adeniyi, J. D., \& kale, O. O. (2008). Health education interventions to control onchocerciasis in the context of primary health care. Primary health care: the African experience, 341-371.

Buddent, F. L. T. (2013). Natural history of Onchocerciasis. Retrieved March 8, 2017, from www.ncbi.nlm.nih.gov/pmc/articles/PMC509535

Eezzuduemhoi, D., \& Wilson, D. (2013). Onchocerciasis eMedicine. Retrieved March 6, 2017 from www.emedicine.com/oph/topic709html.

Hoerauf, A., Buttner, D. N., Adjei, O., \& Pearlman, E. (2003). Onchocerciasis. BMJ, 326, 20710. https://doi.org/10.1136/bmj.326.7382.207

Manafa, O. U., Awolola, T. S., \& Isamah, A. (2003). Effectiveness of motivational strategies in sustaining compliance with community ivermectin therapy. International Quarterly of Community Health Education, 2, 177-189.

Manafah, O. U., \& Isamah, A. N. (2002). Local knowledge an attitude about onchocerciasis in Oji River Local Government area of Enugu State, Nigeria. https://doi.org/10.1017/S0950268802007574

Mbanefo, E. C., Eneanya, C. L., Nwaorgu, O. C et al. (2010). Onchocerciasis in Anambra State, Southeast Nigeria: Clinical and Psychological aspects and sustainability of community directied treatment with Ivrmectin (CDTI). Post grad Med J, 573-577. https://doi.org/10.1136/pgmj.2010.100248

Nandha, B., \& Krishnamoorthy, K. (2011). Impact of education compaign on community based vector control in hasterning Nadu, South India. Retrieved February 15, 2017, from www.heroxfordjournal.org/conten/early/2011/07/01/ner.cyr045.full

Nigeria Business Directory and Nigerian Information Enugu State, Nigeria. (2013). www.ngex.com.nigeria/places/states/enugu.html.Accessed April 25

Nwoke, B. E. B. (2013). The Socio-economic aspects of human onchocerciasis in Africa: Present appraisal. Retrieved March 8, 2017, from www.ncbi.nlm.nih.gov/pubmed/235181e.Accessed 
Ogbuokiri, J. E. (2013). Strategies for improving health of residents in rural Nigeria: Cost effectiveness of a women's health cooperative versus ministry works in Ivermectin (Mectizan). Retrieved from distribution.www.hsph.harvard.ed

Opara, K.N., Usip, I. P., \& Akpabio, E. E. (2008). Transmission dynamics of Simulium dannosum in rural communities of Akwa Ibom State. Nigeria J Vector Borne, 45, 225-230.

Shu, E. N., Nwadike, K. I., Onwujekwe, E. O., Ugwu, O. C., \& Okonkwo, P. O. (1999). Influence of health education on community participation in rapid assessment of onchocerciasis prior to distribution of ivermetin. East Afr Med J, 76(6), 320-3.

Shu, E.N., Okonkwo, P. O., \& Onwujekwe, E. O. (2008). Health education to school children in Okpatu, Nigeria: impact on onchocerciasis-related knowledge. In infections and Tropical Disease. Leeds Health Education Data Base: Database entries with complete fields. Retrieved February 15, 2017, from www.hubley.co.uk/infectdis.htm

Weldegereal, F., Medhin, G., Weldegbriel, Z., \& Legesse, M. (2014). Assessment of community's knowledge, attitude and practice about onchocerciasis and community directed treatment with ivermectin Quara District, north western Ethiopia. Parasites and Vectors, 7, 98. https://doi.org/10.1186/1756-3305-7-98

World Health Organization. (2012). Expert Committee on the epidemiology of Onchocerciasis. WHO Technical Report Series No. 597. Retrieved March 8, 2017, from www.app.who.int/int/iris/handle/10665/41213

World Health Organization. (2013). Onchocerciasis and its control. Report of a WHO Expert Committee on Onchocerciasis Control. Technical Report Series. Retrieved March 4, 2017, from www.ncbi.nlm.nih.gov/m/pubmed/7541171

World Health Organization. (2015). The importance of Onchocercial Skin Disease. Retrieved March 4, 2017, from www.who.int/tdrpublications/tdr-research-publications/oncho-sk9in-disease/en/index.html

World Health Organization/African Programme for Onchocerciasis Control. (2013). Community Directed Treatment with Ivermetin: Sustainability and Ownership. Retrieved from http://www.who.intblindness/partnerships/APOC/en/Accessed February 4

World Health Organizations. (1995). Onchocerciasis and its control. Report of a WHO Expert Committee on Onchocerciasis control. Geneva. Technical report series no. 852.

\section{Copyrights}

Copyright for this article is retained by the author(s), with first publication rights granted to the journal.

This is an open-access article distributed under the terms and conditions of the Creative Commons Attribution license (http://creativecommons.org/licenses/by/4.0/). 